\title{
Low Prevalence of Protein Energy Wasting in Advanced Chronic Kidney Disease Patients Managed with a Nutritional Monitoring Program
}

\section{Guillermina Barril*, Angel Nogueira, Graciela Alvarez, Almudena Nuñez, Carmen Sanchez and Paula Romasco}

Department of Nephrology, Hospital Universitario de la Princesa, Madrid, Spain

*Corresponding Author: Guillermina Barril, Department of Nephrology, Hospital

Universitario de la Princesa, Madrid, Spain.
Received: November 18, 2021

Published: December 14, 2021

(C) All rights are reserved by Guillermina

Barril., et al.

\section{Abstract}

Objectives: To analyze the prevalence of Protein Energy Wasting (PEW) in Advanced Chronic Kidney Patients (ACKD) using monitoring tools normally used in the multidisciplinary CKD Unit. To assess the differences in nutritional parameters, body composition and muscle strength between patients with and without PEW.

Design and Method: Retrospective cross sectional study of patients from the ACKD Unit. The study included outpatient consultations offering specialized care for ACKD in the multidisciplinary hospital unit. We performed an initial nutritional assessment with screening and a complete baseline assessment followed by screening at each consultation (minimum every 3 months) and complete assessment every 6 months or if malnutrition appeared in the screening of risk. We performed screening and complete evaluation with biochemical parameters, body composition assessed by vectorial-bioimpedance and anthropometry, and hand grip strength measurement. PEW was diagnosed according to international society of renal nutrition and metabolism (ISRNM) criteria.

Results: We found a PEW prevalence of 9.1\% (29/320 patients) without significant differences between men and women. The mean age of the patients with PEW was higher than that of non-PEW patients ( $74.58 \pm 12.84$ vs $70.54 \pm 12.37$ ), although the difference was not statistically significant.

We observed significant differences in biochemical parameters, vectorial bioimpedance and anthropometric values, and hand grip strength between patients with and without PEW. A multivariate regression analysis showed that age, transferrin, $\%$ fat-free-mass, $\%$ total body water and phase-angle were predictive factors for PEW. Of them, phase angle was the best predictive factor.

Conclusions: The use of nutritional status monitoring protocols results in low prevalence of PEW and allows its early detection, thereby favoring the reversion of this condition with the appropriate intervention. An adequate nutritional status monitoring is a priority for the integral care of patients at ACKD Units.

Keywords: Advanced Chronic Kidney Disease Unit (ACKD); Protein Energy Wasting (PEW); Malnutrition; Inflammation

\section{Introduction}

Chronic kidney disease (CKD) has been recognized as a global health problem that associates with cardiovascular risk. The prevalence of malnutrition in patients with chronic kidney disease
(CKD) is high. This condition is related to modifiable factors such as caloric-protein intake, reversible comorbidities associated or not with CKD, inflammatory status, and socioeconomic level, as well as to non-modifiable factors such as retention of uremic toxins due to CKD, age, and gender [1,2]. 
In 2008, the International Society of Renal Nutrition and Metabolism (ISRNM) described a syndrome in hemodialysis (HD) patients called Protein Energy Wasting (PEW). Criteria defining this syndrome encompass alterations that appear in renal patients due to a combination of toxin retention, endocrine metabolic disorders and low intakes, which are interrelated with inflammatory processes causing a syndrome characterized by wasting losses of the lean body mass and fat body mass compartments that increase mortality [3-6].

Diagnosis criteria are divided into four categories (biochemical parameters, body composition, muscle mass, and protein and energy intake). The ISRNM proposed that PEW could be diagnosed when the following criteria are met in three out of the four proposed categories: low levels of biochemical indicators (i.e., albumin, transthyretin or cholesterol), decreased body mass (i.e., body mass index, unintentional weight loss and body fat percentage), reduced muscle mass (i.e., muscle wasting or sarcopenia and reduced mid-arm muscle circumference), and unintentional low dietary intake (i.e., energy and protein intake). These criteria must be sustained for a minimum time to be considered for PEW diagnosis [3].

Preventing PEW is one of the most pressing objectives in the management of advanced CKD patients. Accordingly, an adequate caloric intake is important in CKD because it contributes to limit excess protein intake, thereby avoiding PEW development [7].

A PEW prevalence of $28-80 \%$ has been reported in HD patients $[8-13]$.

Although initially described in HD patients, PEW has been later reported in non-dialysis advanced CKD (ACKD) patients. In these patients PEW prevalence increases with CKD progression, showing the highest values in stage 5 [11]. Several studies have reported that the prevalence is less than $2 \%$ in stages $1-2$ [9,10], 11-46\% in stages 3-5 [10-13]; the last meta-analysis described $28-54 \%$ prevalence in 16434 HD patients and 11-54\% in stages 3-5 [11-19].

PEW diagnosis is dependent of a wide variety of parameters assessed by different tools. Cut-off points to establish normality ranges for these parameters may vary with ethnicity, sex and environmental factors of the study population, thereby determining the great variability of PEW prevalence values across different studies, especially in HD patients (where more studies have been published), but also in peritoneal dialysis or ACKD [18,19].
An adequate monitoring of the nutritional status in patients with CKD, mainly in non-dialysis patients in stages $3 \mathrm{~b}, 4$ and 5 , has been reported to reduce PEW rates and its associated cardiovascular mortality [11].

The aim of this study was to analyze the prevalence of PEW in ACKD patients undergoing nutritional assessment with the monitoring program normally used in our multidisciplinary CKD Unit. The secondary aim was to establish the relationship of PEW with the nutritional parameters, body composition, and muscle strength used for nutritional assessment.

\section{Materials and Methods}

\section{Study design and population}

This was a retrospective cross-sectional study carried out with anonymous data collected from outpatients of the Advanced Chronic Kidney Disease Unit in Madrid who underwent a nutritional monitoring program. The study included outpatient consultations offering specialized care for ACKD in the multidisciplinary hospital unit. The inclusion criteria were: patients older than 18 years, CKD stages 3b, 4 and 5 without dialysis, without cognitive impairment, who had at least two outpatient consultations with a complete nutritional assessment ( 6 months) and had all the parameters collected. Exclusion criteria: patients who refused the full assessment or those who could not make any of the routine determinations included in the study.

\section{Nutritional monitoring program}

- The ACKD multidisciplinary Unit performs a nutritional monitoring program with initial screening and a complete baseline assessment, screening at each consultation (minimum every 3 months), and a complete assessment every 6 months or if malnutrition appears in the screening of risk (Figure 1).

- The assessment frequency may increase if the Malnutrition Screening Tool (MST) (screening test) detects malnutrition and/or if the patient requires hospital admission.

- $\quad$ According to the assessment, dietary advice was provided as well as nutritional intervention if required.

PEW was diagnosed in ACKD patients using ISRNM criteria. To analyze difference in nutritional parameters, body composition 


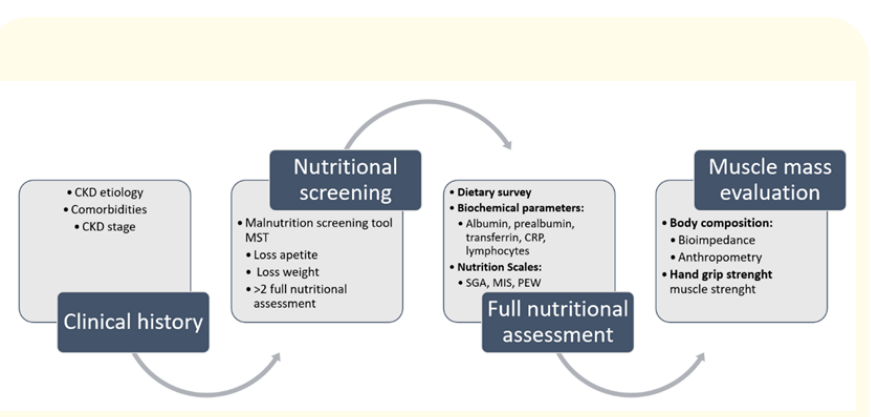

Figure 1: Algorithm of nutritional assessment in the ACKD Unit.

Malnutrition Screening Tool (MST), C-reactive protein (CRP), Subjective global assessment of nutritional status (SGA), Malnutrition-Inflammation Score (MIS), Protein Energy Wasting (PEW), Bioelectrical impedance analysis (BIA).

and muscle strength associated with PEW, patients were classified in two groups: Group 1 (G1), PEW patients, and group 2 (G2), nonPEW patients.

The following parameters were collected:

- General parameters: Age, gender, time in the ACKD Unit, diabetes, weight, height and comorbidities

- Laboratory parameters: Proteins (albumin, transferrin, prealbumin), C-reactive protein (CRP) as an inflammation parameter, total lymphocytes, hemoglobin ( $\mathrm{Hb})$, cholesterol, creatinine.

- Body composition assessed by using Akhern BIA 101 monofrequency vector bioimpedance: phase angle, exchangeable $\mathrm{Na} / \mathrm{K}$, cell mass, total body water, intracellular water, extracellular water, lean mass, fat mass, muscle mass, cell mass index and body mass index (BMI).

- Anthropometric measurements: Waist circumference and brachial circumference (brachial circumference) measured with inextensible measuring tape "Cescorf"; tricipital skin fold (tricipital fold) measured with a "Holtain" Caliper, and muscle mass circumference (arm muscle circumference) determined with the formula MAC = brachial circumference $(3,1416 \times$ triccipial skin fold $\mathrm{cm})$

- Muscle strength measured with hand grip strength (dynamometer) (baseline model 12-0240).
Parameters were collected at each nutritional assessment. PEW diagnosis and variables used for statistical analysis were those collected at the second assessment.

\section{Statistical analysis}

Data were collected in an Excel database specifically created for this study.

Quantitative variables of are represented as mean and standard deviation, Quantitative variables were compared with the Student's test or non-parametric tests as appropriate. Categorical variables were compared using the chi-square test or Fisher's exact test. We performed also the univariate regression analysis to stablish the association of multiple biochemical nutritional and anthropometric parameters and multivariate analysis to choice the best model adjusted.

All statistical analyses were carried out with the SPSS 23 statistical program (IBM Corp. Released 2015. IBM SPSS Statistics for Windows, Version 23.0. Armonk, NY: IBM Corp).

\section{Results}

A total of 320 patients of the multidisciplinary ACKD Unit were included in the study. Mean age was $70.90 \pm 12.45$ years, $214(66.9 \%)$ patients were men and 106 (33.1\%) were women. Twenty-seven (8.4\%) patients were in stage G3b, 181 (56.6\%) in G4, and 112 (35\%) in G5. The mean CKD-EPI was $18.58 \pm 7.64 \mathrm{ml} /$ $\min / 1.73 \mathrm{~m}^{2}$.

Prevalence of PEW was 9.1\% (29/320 patients), without significant difference between men and women. Data on demographic and biochemical parameters of patients with and without PEW are shown in table 1.

Mean age was higher in patients with PEW compared with nonPEW patients $(74.58 \pm 12.84$ years vs $70.54 \pm 12.37)$, although this difference was not statistically significant. While difference of mean age was not observed between these groups in men, women showed statistically significant differences ( $p=0.041)$.

The values of biochemical parameters and body composition in patients with PEW were striking, as some of them were close to the low limit of normality. These results suggested that the altered parameters could be reversed if they were diagnosed and intervened on time. 


\begin{tabular}{|l|c|c|c|}
\hline Parameter & $\begin{array}{c}\text { With PEW (G1) } \\
(\mathbf{n = 2 9 )}\end{array}$ & $\begin{array}{c}\text { Without PEW (G2) } \\
(\mathbf{n = 2 9 6 )}\end{array}$ & $\mathbf{p}$ \\
\hline Age (years) & $74.58 \pm 12,84$ & $70.52 \pm 12.37$ & $\mathrm{~ns}$ \\
Male & $\begin{array}{c}7.27 \pm 14,23 \\
\text { Female }\end{array}$ & $\begin{array}{c}70.44 \pm 11.22 \\
70.74 \pm 14.52\end{array}$ & 0.041 \\
\hline $\begin{array}{l}\text { Gender } \\
\text { Male }\end{array}$ & $18(62 \%)$ & $196(67.3 \%)$ & $\mathrm{ns}$ \\
Female & $11(38 \%)$ & $95(32.7 \%)$ & 0.08 \\
\hline nPNA (gr/kg/ & $0.73 \pm 0.21$ & $0.93 \pm 0.26$ & 0.003 \\
day) & $3.77 \pm 0.67$ & $4.20 \pm 0.41$ & 0.002 \\
\hline Albumin (gr/dl) & $1.17 \pm 2.05$ & $0.68 \pm 1.21$ & 0.06 \\
\hline CRP & $201,6 \pm 48.61$ & $224.76 \pm 40.10$ & 0.017 \\
\hline $\begin{array}{l}\text { Transferrin } \\
\text { (mg/dl) }\end{array}$ & $11.30 \pm 1.53$ & $11.96 \pm 1.48$ & 0.023 \\
\hline $\begin{array}{l}\text { Hemoglobin } \\
\text { (gr/l) }\end{array}$ & & & \\
\hline
\end{tabular}

Table 1: Sociodemographic and biochemical parameters in ACKD patients according to PEW.

Categorical variables are expressed as number (\%) and quantitative variables as mean \pm standard deviation. Differences were analyzed by student $t$-test for quantitative variables and by Chi square test for categorical variables, $\mathrm{p} \leq 0.05$ was considered statistically significant.

Abbreviations. CRP: C-reactive Protein; nPNA: Normalized Nitrogen Protein Appearance; ns: Not Significant; PEW: Protein Energy Wasting.

Table 2 shows mean values of body composition parameters of patients with PEW and non-PEW patients. These data showed significant differences in phase angle, exchangeable $\mathrm{Na} / \mathrm{K}, \%$ cell mass, \% total body water and, as expected, intracellular water as an indirect indicator of muscle mass. Likewise, patients with PEW presented lower mean triceps fold, as a measure of subcutaneous body fat, body surface area and waist circumference.

\begin{tabular}{|l|c|c|c|}
\hline Parameter & $\begin{array}{c}\text { With } \\
\text { PEW (G1) }\end{array}$ & $\begin{array}{c}\text { Without } \\
\text { PEW (G2) }\end{array}$ & p \\
\hline Phase Angle & $3.43 \pm$ & $4.21 \pm 1.15$ & 0.001 \\
\hline Exchangeable Na/K & 1.23 & & \\
\hline \%Body cell mass & $0.67 \pm$ & $1.39 \pm 0.46$ & 0.001 \\
& $33.27 \pm$ & $39.07 \pm 9.23$ & 0.002 \\
\hline
\end{tabular}

\begin{tabular}{|c|c|c|c|c|}
\hline \multicolumn{2}{|c|}{ \% Total Body Water } & $\begin{array}{c}57.68 \pm \\
7.86\end{array}$ & $53.23 \pm 6.88$ & 0.001 \\
\hline \multicolumn{2}{|c|}{$\begin{array}{l}\text { \%Intracellular Body } \\
\text { Water }\end{array}$} & $\begin{array}{c}38.42 \pm \\
10.38\end{array}$ & $43.82 \pm 8.12$ & 0.001 \\
\hline \multicolumn{2}{|l|}{$\%$ Fat Mass } & $\begin{array}{c}25.63 \pm \\
11.24\end{array}$ & $32.21 \pm 9.17$ & 0.005 \\
\hline \multicolumn{2}{|c|}{$\%$ Fat Free Mass } & $\begin{array}{c}74.36 \pm \\
11.24\end{array}$ & $67.75 \pm 9.31$ & 0.001 \\
\hline \multicolumn{2}{|l|}{ BMI } & $\begin{array}{c}24.80 \pm \\
4.89\end{array}$ & $27.64 \pm 4.99$ & 0.004 \\
\hline \multicolumn{2}{|c|}{ Body Cell Mass Index } & $\begin{array}{c}5.91 \pm \\
2.77\end{array}$ & $7.02 \pm 2.11$ & 0.009 \\
\hline \multicolumn{2}{|c|}{ Brachial Circumference } & $\begin{array}{c}26.24 \pm \\
4.79\end{array}$ & $27.64 \pm 4.40$ & 0.001 \\
\hline \multicolumn{2}{|c|}{ Tricipital Skin Fold } & $\begin{array}{c}15.12 \pm \\
0.86\end{array}$ & $18.52 \pm 9.41$ & 0.072 \\
\hline \multicolumn{2}{|c|}{$\begin{array}{l}\text { Muscle Mass Circumfer- } \\
\text { ence }\end{array}$} & $\begin{array}{c}25.97 \pm \\
4.39\end{array}$ & $28.38 \pm 4.04$ & 0.004 \\
\hline \multicolumn{2}{|c|}{ Waist Circumference } & $\begin{array}{c}90.05 \pm \\
22.16\end{array}$ & $\begin{array}{c}99.68 \pm \\
14.93\end{array}$ & 0.020 \\
\hline \multicolumn{2}{|c|}{ Body Surface Area } & $\begin{array}{c}1.74 \pm \\
0.21\end{array}$ & $1.83 \pm 0.22$ & 0.038 \\
\hline $\begin{array}{l}\text { HGS Right } \\
(\mathrm{kg})\end{array}$ & $\begin{array}{l}\text { Overall } \\
\text { Male } \\
\text { Female }\end{array}$ & $\begin{array}{c}20.96 \pm \\
11.24 \\
23.72 \pm \\
12.21 \\
16.45 \pm \\
8.01\end{array}$ & $\begin{array}{c}25.22 \pm \\
10.46 \\
29.21 \pm 9.82 \\
16.98 \pm 5.99\end{array}$ & $\begin{array}{c}0.039 \\
0.027 \\
\text { ns }\end{array}$ \\
\hline HGS Left (kg) & $\begin{array}{l}\text { Overall } \\
\text { Male } \\
\text { Female }\end{array}$ & $\begin{array}{c}20.13 \pm \\
8.70 \\
21.83 \pm \\
9.70 \\
17.36 \pm \\
6.20\end{array}$ & $\begin{array}{c}23.14 \pm \\
10.17 \\
26.89 \pm 9.90 \\
15.53 \pm 5.28\end{array}$ & $\begin{array}{c}\text { ns } \\
0.039 \\
\text { ns }\end{array}$ \\
\hline
\end{tabular}

Table 2: Body composition and muscle strength parameters in ACKD patients according to PEW.

All variables are expressed as mean \pm standard deviation. Differences were analyzed by student $t$ test, $\mathrm{p} \leq 0.05$ was considered statistically significant.

Abbreviations. BMI: Body Mass Index; HGS: Hand Grip Strength; ns: Not Significant; PEW: Protein Energy Wasting. 
Phase angle values were further grouped into quartiles with upper limits of Q1:3.30, Q2: 4.1, Q3:4.9, Q4:5.7. Percentages of patients with PEW (G1) compared to those without PEW (G2) in the different quartiles were: $55.2 \%$ (16 patients) vs $23.7 \%$ (67 patients) in Q1, $17.2 \%$ (5) vs $26.8 \%$ (7) in Q2, $17.2 \%$ (5) vs $23 \%$ (67) in $\mathrm{Q} 3$, and $10 \%$ (3) vs $26.5 \%$ (77) in Q4, p $=0.003$. These results showed that phase angle values in PEW patients were mainly found in Q1.

Muscle strength measured by right hand grip strength was lower in patients with PEW compared to non-PEW patients $(20.96 \pm$ $11.24 \mathrm{Kg}$ vs $25.22 \pm 10.46 \mathrm{Kg}, \mathrm{p}=0.039$ ). While this parameter was also lower in male patients, it did not show difference in females patients (table 2, cut-off point according to the European sarcopenia group EWGSOP 2019: $27 \mathrm{~kg}$ in men and $16 \mathrm{~kg}$ in women).

We carried out a univariate regression model to assess the effect of the different parameters on the appearance of PEW (Table 3). Most of the parameters analyzed were associated with PEW.

\begin{tabular}{|l|c|c|}
\hline Variable & OR (95\% CI) & p \\
\hline Age & $0.970(0.936-1.006)$ & 0.097 \\
\hline Phase Angle & $1.993(1.329-2.988)$ & 0.001 \\
\hline Exchangeable Na/K & $0.291(0.159-0.533)$ & 0.001 \\
\hline \%Body Cell Mass & $1.071(1.025-1.120)$ & 0.002 \\
\hline \%Total Body Water & $0.913(0.864-0.966)$ & 0.002 \\
\hline \%Intracellular Body Water & $1.079(1.030-1.131)$ & 0.001 \\
\hline \%Fat Mass & $1.077(1.033-1.124)$ & 0.001 \\
\hline \%Fat Free Mass & $0.929(0.891-0.969)$ & 0.001 \\
\hline Body Cell Mass Index & $1.302(1.063-1.595)$ & 0.011 \\
\hline Brachial Circumference & $1.157(1.056-1.268)$ & 0.002 \\
\hline Muscle Mass Circumference & $1.157(1.042-1.284)$ & 0.006 \\
\hline Waist Circumference & $1.030(1.008-1.052)$ & 0.006 \\
\hline Body Surface Area & $6.179(1.061-35.972)$ & 0.043 \\
\hline Hemoglobin & $1.376(1.055-1.796)$ & 0.019 \\
\hline Transferrin & $1.010(1.002-1.018)$ & 0.017 \\
\hline Right Hand Grip Strength & $1.042(1.002-1.084)$ & 0.039 \\
\hline
\end{tabular}

Table 3: Univariate regression analysis of the association between different nutrition and anthropometric parameters and PEW.

Analysis was carried out by...test. $\mathrm{p} \leq 0.05$ was considered statistically significant.
The multivariate regression analysis showed that age, transferrin, \% fat free mass, \%total body water and phase angle were predictive factors for PEW; of these parameters, phase angle showed the highest predictive capacity (Figure 2).

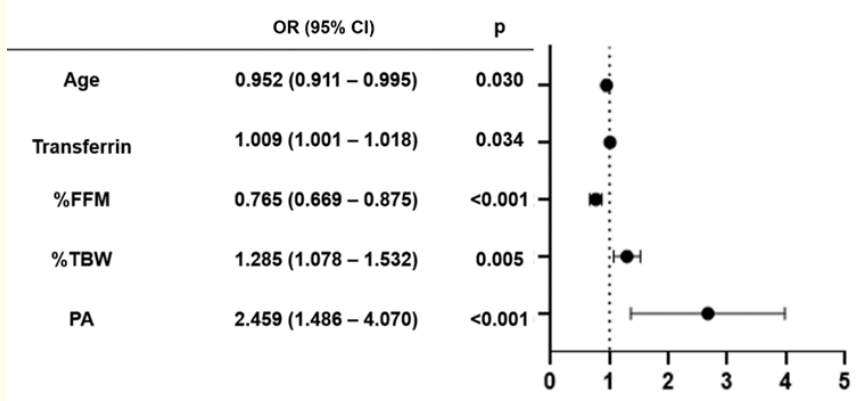

Figure 1: Multivariate regression analysis of factors associated with PEW.

Abbreviations. FFM: Fat Free Mass; CI: Confidence Interval; OR: Odds Ratio; TBW: Total Body Water; PA: Phase Angle.

\section{Discussion}

The incidence of PEW in CKD patients described in the literature is high, although ranges reported vary considerably among different studies [8-11].

In 1983, the World Health Organization adopted the term "wasting" to refer to an involuntary loss of more than $10 \%$ of patient's basal weight in the absence of opportunistic infection, cancer or chronic diarrhea [11,22].

Wasting is often present in CKD in response to anorexia-induced insufficient energy and protein intake in addition to other alterations in which inflammation commonly appears.

Cachexia is considered by the Society on Sarcopenia, Cachexia and Wasting Disorders as a complex syndrome associated with underlying illness and characterized by loss of muscle mass, with or without loss of fat mass [22].

In 2008, the IRSNM proposed a specific classification of uremia induced wasting disorders (Protein Energy Wasting) in which cachexia was the most severe stage $[5,21,22]$.

Abbreviations. CI: Confidence Interval; OR: Odds Ratio. 
PEW is considered as a state of nutritional and metabolic disorder in patients with CKD characterized by simultaneous loss of systemic body protein and energy stores, leading ultimately to loss of muscle and fat mass and cachexia [5,22].

The terms PEW and cachexia appeared in more than 300 and 200 CKD publications, respectively; cachexia is currently considered as a final stage of PEW in which reversibility is practically nil [11].

In CKD, factors such as malnutrition hypercatabolic stage, uremic toxins and increased release of serum inflammatory cytokines, caused in part by uremic toxin stimulation, may contribute to PEW pathogenesis [23-26].

The PEW syndrome was originally described in hemodialysis patients but has subsequently been characterized in CKD patients without dialysis; in addition, the prevalence of PEW has been shown to increase as CKD progresses [11].

The difference of PEW prevalence ranges among different studies, likely due to differences in the cut-off points used to establish normality values for the parameters within the PEW diagnosis criteria, which may vary according to factors such as ethnicity and geographical location, among others. Therefore, cut-off choice is crucial for PEW prevalence assessment. In this sense, muscle mass and strength may vary according to the normality cut-off points chosen. In the present study we chose for these parameters the 2019 criteria of the European Working Group on Sarcopenia [27].

Frailty and sarcopenia closely correlate with PEW, muscle wasting and cachexia. Prevention and treatment of PEW should offer individualized and full care approaches to early risk factor detection and target associated comorbidities.

It is worth remarking that the prevention and early treatment of PEW can contribute to reverse this condition. Therefore, using adequate PEW diagnosis criteria and nutritional status monitoring using different scoring tools is important for its management [11].

Our results showed that combining nutritional parameters, close assessment of body composition and muscular strength by hand grip strength can contribute to a complete evaluation of the status of these patients. In addition, Malnutrition inflammation Score (MIS phase angle and hand grip strength have been consid- ered as factors associated to increase in morbidity and mortality. Therefore, taken together, all these tools could help to better assess PEW beyond ISRNM criteria [4].

PEW is closely associated with morbi-mortality in ACKD patients, especially in those in G3b, G4 and G5 CKD stages [7,11]. For this reason, we studied our patients in these advanced CKD stages. However, despite the mean CKD-EPI of our patients was $18.58 \pm$ $7.64 \mathrm{ml} / \mathrm{min} / 1.73 \mathrm{~m}^{2}$ and more than $50 \%$ of them were in G4 stage, PEW prevalence was low.

Old age and advanced disease stages are factors that predispose to malnutrition. In our study population mean age was high and most patients were in G4 and G5 stages. Therefore, high prevalence could be expected. However, the PEW prevalence found in patients of our ACKD Unit was 9,1\%, which was lower than the range (11$46 \%$ ) previously reported for CKD 3-5 stages [7,11].

In this study we have demonstrated that adequate monitoring of nutritional status could help to prevent the appearance or decrease the prevalence of PEW, even in elderly patients with advanced CKD.

We observed significant differences in biochemical and body composition parameters between patients with PEW and nonPEW patients. Mean albumin, transferrin and $\mathrm{Hb}$ values were significantly lower in patients with PEW, although transferrin and $\mathrm{Hb}$ are not included as parameters within the PEW criteria. Although the patients studied did not have a high degree of inflammation in any group, CRP values were higher in the group with PEW, but the difference was at the limit of significance.

As expected, body composition parameters, assessed by vector bioimpedance and anthropometry, were better in patients without PEW. As previously described in the literature, these patients showed better phase angle and better intracellular water indicating better muscle mass as well as better muscle arm circumference. It is worth remarking that considering quartile distribution of phase angle in our patients, more than $50 \%$ of patients with PEW showed phase angles in Q1, in agreement with results reported in the literature [28,31].

Hand grip strength has proven to be a good tool to assess the risk of malnutrition and inflammation in HD and a good predictive factor for survival $[32,33]$. Our univariate analysis showed that this 
parameter was associated with PEW. In addition, right hand dynamometry was significantly better in patients without PEW; while this parameter was also better in male patients without PEW, it did no show statistically significant differences in female patients.

The univariate regression analysis showed the association of multiple biochemical nutritional and anthropometric parameters with PEW, such as phase angle, exchangeable $\mathrm{Na} / \mathrm{K}, \%$ body cell mass, $\%$ total body water, $\%$ intracellular body water, $\%$ fat mass, $\%$ fat free mass, body cell mass index, brachial circumference, muscle arm muscle circumference, waist circumference, body surface area, hemoglobin, transferrin and right hand grip strength. In the multivariate analysis, age, total body water, lean mass and phase angle remained significantly associated with PEW. Of these variables, phase angle showed the highest predictive value.

\section{Conclusion}

- $\quad$ The use of nutritional status monitoring protocols results in low prevalence of PEW and allows its early detection, thereby favoring the reversion of this condition with the appropriate intervention.

- An adequate nutritional status monitoring is a priority for the integral care of patients at ACKD Units.

\section{Practical Application}

Implementation of a good Nutritional Monitoring Program for advanced chronic kidney disease patients can help in the adequate assessment of their nutritional status. This favors earlier diagnosis and prevention of malnutrition reducing the appearance of the PEW syndrome.

\section{Acknowledgement}

To Manuel Gomez from Hospital de la Princesa Institute for his help with the English version.

\section{Authors' Contributions}

Guillermina Barril, Angel Nogueira y Graciela Alvarez wrote the main manuscript Almudena Nuñez, Carmen Sanchez y Paula Romasco help in the clinical practice All authors have read and approved this information before submission.

\section{Funding}

Not applicable.

\section{Availability of Data and Materials}

The datasets used and/or analysed during the current study are available from the corresponding author on reasonable request.

\section{Ethics Approval and Consent to Participate}

This research was approved by the Research Ethics Commitee of Hospital Universitario de la Princesa (No. 4342) and was conducted according to the ethical principles contained within the Declaration of Helsinki.

Inform consent was not required because this is a retrospective study in which the data was retrieved from patients' medical histories from regular clinical practice.

\section{Consent for Publication}

Not applicable.

\section{Competing Interests}

Guillermina Barril has received honorarium for conference and course from: Abbott, Nutricia, Nestlé, Rubió. The other authors declare that they have no competing interests.

\section{Availability of Data and Materials}

The datasets used and/or analysed during the current study are available from the corresponding author on reasonable request.

\section{Bibliography}

1. Lopes AA., et al. "Independent and joint associations of nutritional status indicators with mortality risk among chronic hemodialysis patients in the Dialysis Outcomes and Practice Patterns Study (DOPPS)". Journal of Renal Nutrition 20.4 (2010): 224-234.

2. Hyun YY., et al. "Nutritional Status in Adults with Predialysis Chronic Kidney Disease: KNOW-CKD Study". Journal of Korean Medical Science 32.2 (2017): 257-263.

3. Fouque D., et al. "A proposed nomenclature and diagnostic criteria for protein-energy wasting in acute and chronic kidney disease". Kidney International 73 (2008): 391-398.

4. Kovesdy CP., et al. "Management of protein-energy wasting in non-dialysis-dependent chronic kidney disease: reconciling low protein intake with nutritional therapy". The American Journal of Clinical Nutrition 97 (2013): 1163-1177. 
5. Moreau-Gaudry X., et al. "A simple protein-energy wasting score predicts survival in maintenance hemodialysis patients". Journal of Renal Nutrition Official Journal of the Council on Renal Nutrition of the National Kidney Foundation 24 (2014): 395-400.

6. Carrero JJ., et al. "Etiology of the protein-energy wasting syndrome in chronic kidney disease: a consensus statement from the International Society of Renal Nutrition and Metabolism (ISRNM)". Journal of Renal Nutrition 23 (2013): 77-90.

7. Ramy M Hanna., et al. "A Practical Approach to Nutrition, Protein-Energy Wasting, Sarcopenia, and Cachexia in Patients". Blood Purification 49 (2020): 202-211.

8. De Mutsert R., et al. "Subjective global assessment of nutritional status is strongly associated with mortality in chronic dialysis patients". American Journal of Clinical Nutrition 89 (2009): 787-793.

9. Sum SS-M., et al. "Comparison of subjective global assessment and protein energy wasting score to nutrition evaluations conducted by registered dietitian nutritionists in identifying protein energy wasting risk in maintenance hemodialysis patients". Journal of Renal Nutrition Official Journal of the Council on Renal Nutrition of the National Kidney Foundation 27 (2017): 325-332.

10. Vegine PM., et al. "Assessment of methods to identify proteinenergy wasting in patients on hemodialysis". Brazilian Journal of Nephrology Orgao of Soc Bras E Lat-Am Nefrol 33 (2011): 55-61.

11. Laetitia Koppe., et al. "Kidney cachexia or protein-energy wasting in chronic kidney disease: facts and numbers". Journal of Cachexia, Sarcopenia and Muscle 10 (2019): 479-484.

12. Dai L., et al. "Clinical global assessment of nutritional status as predictor of mortality in chronic kidney disease patients". PLoS ONE 12 (2017): e0186659.

13. Pérez-Torres A., et al. "Protein-energy wasting syndrome in advanced chronic kidney disease: prevalence and specific clinical characteristics". Nefrologia (England Ed) 38 (2018): 141-151.

14. Campbell KL., et al. "Evaluation of nutrition assessment tolos compared with body cell mass for the assessment of malnutrition in chronic kidney disease". Journal of Renal Nutrition Of- ficial Journal of the Council on Renal Nutrition of the National Kidney Foundation 17 (2007): 189-195.

15. Cupisti A., et al. "Nutritional status and dietary manipulation in predialysis chronic renal failure patients". Journal of Renal Nutrition Official Journal of the Council on Renal Nutrition of the National Kidney Foundation 14 (2004): 127-133.

16. Kim JC., et al. "Frailty and protein-energy wasting in elderly patients with end stage kidney disease". Journal of the American Society of Nephrology 24.3 (2013): 337-351.

17. Carrero JJ., et al. "Global prevalence of protein-energy wasting in kidney disease: a meta-analysis of contemporary observational studies from the international society of renal nutrition and metabolism". Journal of Renal Nutrition Official Journal of the Council on Renal Nutrition of the National Kidney Foundation 28 (2018): 380-392.

18. Gracia-Iguacel C., et al. "Prevalencia del desgaste proteicoenergético y su asociación con mortalidad en pacientes en hemodiálisis en un centro de España". Nefrología 33.4 (2013): 495-505.

19. Ruperto M., et al. "Predictors of protein-energy wasting in haemodialysis patients: a cross-sectional study". Journal of Human Nutrition and Dietetics 29.1 (2014): 38-47.

20. Wang $\mathrm{XH}$ and Mitch WE. "Mechanisms of muscle wasting in chronic kidney disease". Nature Reviews Nephrology 10 (2014): 504-516.

21. Obi Y., et al. "Latest consensus and update on proteinenergy wasting in chronic kidney disease". Current Opinion in Clinical Nutrition and Metabolic Care 18.3 (2015): 254-262.

22. Evans WJ., et al. "Cachexia: a new definition". Clinical nutrition (Edinburgh, Scotland) 27 (2008): 793-799.

23. John SG., et al. "Natural history of skeletal muscle mass changes in chronic kidney disease stage 4 and 5 patients: an observational study". PLoS One 8.5 (2013): e65372.

24. De Mutsert R., et al. "Excess mortality due to interaction between protein-energy wasting, inflammation and cardiovascular disease in chronic dialysis patients". Nephrol Dial Transplant Off Publ Eur Dial Transpl Assoc - Eur Ren Assoc 23 (2008): 2957-2964.

Citation: Guillermina Barril., et al. "Low Prevalence of Protein Energy Wasting in Advanced Chronic Kidney Disease Patients Managed with a Nutritional Monitoring Program". Acta Scientific Nutritional Health 6.1 (2022): 19-27. 
25. Sharma R., et al. "Association of IL-6, IL-10, and TNF- $\alpha$ gene polymorphism with malnutrition inflammation syndrome and survival among end stage renal disease patients". Official Journal of Interferon and Cytokine Research 33 (2013): 384-391.

26. Vanholder R., et al. "Biochemical and Clinical Impact of Organic Uremic Retention Solutes: A Comprehensive Update". Toxins 10.1 (2018): 33.

27. Cruz-Jentoft AJ., et al. Writing Group for the European Working Group on Sarcopenia in Older People 2 (EWGSOP2), and the Extended Group for EWGSOP2. "Sarcopenia: revised European consensus on definition and diagnosis". Age Ageing 48.1 (2019): 16-31.

28. Saitoh M., et al. "Bioelectrical impedance analysis-derived phase angle as a determinant of protein-energy wasting and frailty in maintenance hemodialysis patients: retrospective cohort study". BMC Nephrology 21.1 (2020): 438.

29. G. Barril A., et al. "Influence of dietary protein intake on body composition in CKD patients in stages 3-5: A cross sectional study". Nefrologia 34 (2018): 647-654.

30. Garlini LM., et al. "Phase angle and mortality: a systematic review". European Journal of Clinical Nutrition 73.4 (2019): 495508.

31. Fatin Athirah Pauzi., et al. "Exploring Metabolic Signature of Protein Energy Wasting in Hemodialysis Patients". Metabolites 10 (2020): 291.

32. Sostisso CF., et al. "Handgrip strength as an instrument for assessing the risk of malnutrition and inflammation in hemodialysis patients". Brazilian Journal of Nephrology 42.4 (2020): 429-436.

33. Oliveira MC., et al. "Handgrip strength in end stage of renal disease. a narrative review". Nutrients 43 (2018): 14.

\section{Assets from publication with us}

- Prompt Acknowledgement after receiving the article

- Thorough Double blinded peer review

- Rapid Publication

- Issue of Publication Certificate

- High visibility of your Published work

Website: www.actascientific.com/

Submit Article: www.actascientific.com/submission.php

Email us: editor@actascientific.com

Contact us: +919182824667 